\title{
REPRESENTAÇÕES JUVENIS EM ESPAÇOS MULTICULTURAIS: A CIDADE, O CINEMA E A ESCOLA DE ARARI/MA
}




\section{REPRESENTAÇÕES JUVENIS EM ESPAÇOS MULTICULTURAIS: A CIDADE, O CINEMA E A ESCOLA DE ARARI/MA}

Resumo:

As relações entre os campos da Educação e Comunicação auxiliam na observação das representações que os jovens de uma realidade sócio-cultural distinta fazem de si mesmo, através das formas de apropriação do filme "Escritores da Liberdade" e das influências do contexto sociocultural na construção de seus significados. Assim, o presente trabalho evidencia em sua análise as formas de construção de relações e identidades juvenis, constituídas por conflitos, contradições e antagonismos.

Palavras chave: Educomunicação; Multiculturalismo; Identidade; Diferença

\section{JUVENILE REPRESENTATIONS IN MULTICUTURAL SPACES: THE CITY, THE CINEMA AND THE SCHOOL OF ARARI/MA}

\section{Abstract:}

The relations between Education and Communication help in the observation of the representations that the young people of a distinct socio-cultural reality make themselves, through the forms of appropriation of the film "Freedom Writers" and the influences of the socio-cultural context at the construction of their meanings. Thus, this work shows in his analysis forms of construction of relations and juvenile identities, consisting of conflicts, contradictions and antagonisms.

Keywords: Educommunication; Multiculturalism; Identity; Difference

REPRESENTACIONES JUVENILES EN ESPACIOS MULTICULTURALES: LA CIUDAD, EL CINA Y LA ESCUELA DE ARARI/MA

Resumen:

Las relaciones entre los campos de la Educación y Comunicación auxilian en la observación de las representaciones que los jóvenes de una realidad sociocultural distinta hacen de sí mismo, por medio de las formas de apropiación del cine "Escritores da Liberdade" y de las influencias del contexto sociocultural en la construcción de sus significados. Así, el presente trabajo evidencia en su análisis las formas de construcción de relaciones y identidades juveniles, constituidas por conflictos, contradicciones y antagonismos.

Palabras Clave: Educomunicación; Multiculturalismo; Identidad; Diferencia 


\section{INTRODUÇÃO}

Para refletir acerca das intersecções entre Educação e Comunicação, é fundamental pensar a escola de forma libertadora e a comunicação como promotora de emancipação. Pensar o Multiculturalismo neste contexto é questão fundamental na sociedade contemporânea, e a mídia envolve-se nesse processo pelo seu papel central na construção de representações e referencias culturais. O diálogo e a comunicação, inatos e fundamentais ao ser humano, devem ser estimulados pela escola. Nesse sentido, a prática educomunicacional pode auxiliar como instrumentos de estímulo a novas posturas.

Tal relação, estabelecida entre os sujeitos e suas representações, nem sempre é pacífica, sendo capaz de fomentar conflitos e tensões. A diferença, caso não trabalhada e refletida, torna-se elemento capaz de deflagrar atos de violência e segregar e violar direitos e igualdades que todos gozam em sua condição humana. A tolerância multicultural, básica a uma postura consciente de suas particularidades, é necessária ao ambiente escolar.

Tais conceitos alicerçam a proposta do presente trabalho, desenvolvida em dois municípios brasileiros: Santa Maria, no Rio Grande do Sul, e Arari, no estado do Maranhão. Aqui, aborda-se a experiência da atividade maranhense, que integrou as atividades da equipe da Universidade Federal de Santa Maria (UFSM) na Operação Catirina do Projeto Rondon. A acadêmica, em parceira com outros estudantes da instituição, desenvolveu ações em sua área de atuação durante o mês de julho de 2010.

\section{METODOLOGIA}

A estrutura metodológica do trabalho divide-se em cinco momentos, caracterizados por uma estrutura não fragmentada que parte de uma análise geral, com debate amplo, para chegar a uma síntese. A primeira delas é a sensibilização, com apresentação do propósito do trabalho e foco da observação; a segunda é a exibição do filme, cujo escolhido foi "Escritores da Liberdade"; a terceira é a mais longa, por ser o espaço para provocação e escuta, com debate amplo e questões provocativas que levam ao aprofundamento da temática; a quarta fecha a discussão com a síntese de palavras-chave e das redes associativas entre as idéias surgidas. Na quinta e última fase cada jovem participante é convidado a produzir um retrato com representações de si mesmo, do outro e do mundo onde está inserido.

Esta é uma construção metodológica própria, fruto da prática no grupo "Educação Com\&Para a Mídia - uma Prática de Sustentabilidade Social e Política" e das reflexões do Grupo de Estudos "Comunicação, Educação e Cidadania”. Para garantir resultados plenos e significativos, busca-se uma metodologia capaz de capturar os mais significativos detalhes da prática educomunicacional. 
Desde modo, a opção foi pelo grupo focal como método prático do processo, e aliou-se a prática dos grupos focais à narratologia para a construção da análise. A atividade em Arari/MA foi integrante das programações do Projeto Rondon no município, e foi possível constatar que muitos jovens participaram com motivações externas. A curiosidade foi uma delas, significativa especialmente entre as meninas, que participaram brevemente da atividade. Alguns tiveram participação expressiva, enquanto outros apenas concordavam com seus pares.

Visto que as instituições municipais e estaduais compartilham o mesmo calendário, todas as escolas estavam em férias durante a atividade (julho/2010). Por isso, os alunos que compõe a amostra são de diferentes instituições de ensino. O total de doze participantes contempla cinco estudantes do Colégio Arariense, quatro do Centro de Ensino Cidade de Arari e três que freqüentam aulas no Centro de Ensino Arimatéia Cisne. Todos eles estão finalizando o Ensino Fundamental, cursando $7^{\circ}, 8^{\circ}$ ou $9^{\circ}$ ano, caracterizando distorções série-idade no município.

O Colégio Arariense conta com 521 alunos (Censo Escolar 2010) e localiza-se no centro da cidade. Sua fundação data de 1944, por iniciativa do padre Clodomir Brandt e Silva. A instituição é privada, todavia, há um convênio entre a escola e a Prefeitura Municipal de Arari, municipalizando o Ensino Fundamental.

O Centro de Ensino Cidade de Arari, criado em 1980, também tem localização central e conta com 468 alunos (Censo Escolar 2010). Há oferta para Ensino Fundamental e Médio, além do Programa Nacional de Inclusão do Jovem (PróJovem Urbano) e da Educação de Jovens e Adultos (EJA).

Já o Centro de Ensino Arimatéia Cisne, fundado em 1948, localiza-se em bairro mais distante do centro da cidade, e conta com 410 estudantes (Censo Escolar 2010). A oferta das escolas é para os Ensinos Fundamental e Médio, no Programa Nacional de Inclusão do Jovem (PróJovem Urbano) e na Educação de Jovens e Adultos (EJA).

O filme escolhido para a atividade foi "Escritores da Liberdade" (Freedom Writers, EUA, 2007). A diversidade cultural é o tema principal do filme e perpassa o enredo e as histórias de vida retratadas pela obra. Dirigido por Richard LaGravenese, o filme aborda os conflitos existentes entre alunos e professores, na convivência diária em uma escola californiana.

\subsection{Um olhar histórico, sócio cultural e político do município de Arari/MA}

O multiculturalismo, quando analisado de forma crítica, leva a questionamentos acerca das origens das diferenças, das hierarquizações e privilégios, assim como leva a posicionamentos críticos à exclusão social (Ribeiro, 2008, p. 
131). As situações que hoje se mostram como hegemônicas resultam de construções culturais já legitimadas socialmente, nos grupos sociais. Identificar as influências do contexto cultural na construção e apropriação de representações de "eu", "outro" e do "mundo" é o principal objetivo do presente trabaIho, e, para isto, foi selecionada a cidade de Arari/MA.

O município de Arari, emancipado em 1864, localiza-se na mesorregião do Norte Maranhense e microrregião do Médio Mearim e fica a 156 quilômetros da capital do estado, São Luís. Desde os primeiros registros históricos sobre Arari, que datam de 1723, a influência religiosa católica foi muito grande. Ela iniciou com a doação de terras para a criação de uma comunidade e construção de uma capela, e continuou na década de 1950, com a presença do padre Clodomir Brandt e Silva.

Foram muitos os habitantes de Arari que fizeram oposição ao padre Brandt e seus seguidores, criando movimentos e grupos políticos rivais. A disputa trouxe crescimento a Arari, já que os opositores do padre criaram para si as mesmas instituições já existentes. Após a morte do padre, o conflito cessou e as ações tornaram-se escassas - Arari viveu um momento de estagnação, sem grandes investimentos.

A situação atual de Arari é mais próspera, com investimentos em estruturas e na economia do município. Mesmo crescendo, a cidade convive com problemas resultantes especialmente da urbanização excessiva. Não há saneamento básico nem uma correta gestão de resíduos, o que leva ao depósito de lixo no rio Mearim, fonte de água do município. Também é comum a falta de água, principalmente nas épocas próximas à Pororoca. $O$ trabalho no campo é pouco procurado - há poucas propriedades que cultivam monoculturas como arroz, feijão e melancia, principal produto de Arari. A pecuária também é desenvolvida, com destaque para a criação do pato Paysandu.

O município conta com 100 escolas, sendo 73 municipais e 27 estaduais, conforme dados da Secretaria Municipal de Educação (2010). A educação básica alcança todas as comunidades ararienses, que contam com pelo menos uma escola. Há duas universidades em Arari - a Universidade Estadual do Maranhão (UEMA) e a Universidade Aberta do Brasil (UAB).

\subsection{Realidade arariense em análise}

A matéria prima de análise do presente trabalho são os registros das conversações dos grupos, organizadas em "ideias-força", capazes de relacionar diferentes falas em torno de conceitos e intuições comuns, conforme Thornton (2005, p. 89). Desta forma, é possível observar ideias reiteradas e singularidades, o que possibilita a construção de esquemas de classificação. Junta-se a tal processo a narratologia como metodologia de análise, capaz de "interpretar dinâmica e sistematicamente a essência do fenômeno obser- 
vado" (Motta, 2007, p. 147).

Em Arari, a cultura regional é cotidiana e ganha novas significações dentro da cidade. A tradição do Bumba Meu Boi é centenária no estado, mantida desde o século XVIII. Crianças e adultos brincam juntos, em uma festa que acontece nos meses de junho e julho. A lenda do Bumba Meu Boi relaciona-se diretamente com a crença nos santos de junho - São Pedro, Santo Antônio e São João.

A cidade de São Luís é conhecida por ser o principal espaço das ações culturais ligadas ao democrático Bumba Meu Boi, contudo, os municípios do interior do estado, como Arari, mantém a tradição já secular. A União de Bumba Meu Boi de Arari, ou simplesmente Boi de Arari, é representante do sotaque de orquestra, com instrumentos de sopro e de corda e roupas adornadas com brilhos e franjas.

O município todo envolve-se nas festividades do Boi, que ganha traços próprios em Arari. Os temas nas canções do Boi de Arari são locais, exaltando as belezas do município, as águas do rio Mearim, que corta o município, e a Pororoca, encontro das águas do mar e do rio. Arari também é conhecida no estado pelo Carnaval de rua, que é tido com um dos melhores do Maranhão, assim como pelo Festival da Melancia, principal produto econômico da cidade.

A realidade educacional em Arari é comparável aos níveis da capital do estado, São Luís. Contudo, as chances de emprego ainda são poucas, desestimulando a permanência dos mais novos - quem tem possibilidade para ir morar em São Luís, acaba deixando o interior. Trabalhar na produção de frutas e na pecuária são as principais atividades nas comunidades ararienses, enquanto na sede do município as chances de emprego são na rede municipal de ensino e na prefeitura municipal.

Para aqueles que permanecem em Arari, as opções são escassas, contudo, a administração municipal e a comunidade já articulam uma nova fonte de renda e emprego no Turismo, que começa a investir em qualificação especializada.

\subsection{Personagens e problemáticas da uma história maranhense}

Em Arari, a fala foi simplificada e fluiu com dificuldades. Os jovens eram, em grande maioria, desconhecidos uns dos outros, e a timidez falou mais alto em muitos momentos. Todos participaram, mas alguns apenas balbuciaram algumas palavras ou conversaram os seus colegas mais próximos. Algumas meninas demonstravam estar envergonhadas, limitando-se a conversar entre si. Contudo, quando o grupo focal começou a fluir, elas também participaram.

No município de Arari, participaram nove meninas e três meninos, estudantes de três diferentes escolas. Um ponto que merece destaque é que, 
diferentemente dos alunos santa-marienses, todos os jovens ararienses ainda estão no Ensino Fundamental $\left(7^{\circ}, 8^{\circ}\right.$ ou $9^{\circ}$ ano). A distorção série-idade alcança $100 \%$ dos participantes, sendo questão recorrente no município.

A participante P1 (menina, 14 anos) começou a falar apenas no final da atividade. Durante as primeiras perguntas, ela apenas observou os demais colegas e às vezes fazia comentários com as colegas sentadas ao seu lado. Ela estuda no Colégio Arariense, e é colega de classe de um dos jovens que participaram da atividade, o P4. Sua última fala mostrou-se contraditória com sua postura ao longo do Grupo Focal, onde ela apenas participou nos últimos questionamentos. Ela afirmou não ter vergonha, contudo, mesmo questionada diretamente, não teve participação expressiva no grupo.

O participante $\mathrm{P} 2$ (menino, 15 anos) permaneceu boa parte do encontro calado. Todavia, ele foi um dos que viu o filme de forma mais atenta, pedindo silêncio para as meninas e discutindo, em alguns momentos, as cenas com a irmã, a participante P6. Ele estuda no Centro de Ensino Cidade de Arari (CEMA) e é colega de P8.

O participante $\mathrm{P}_{3}$ (menino, 14 anos) contou com naturalidade que havia sido vítima de violência física na escola. Sobre o incidente, os demais alunos não demonstraram surpresa ou indignação, nem mesmo quando o jovem mostrou as cicatrizes em seu pescoço. Mesmo não sendo o mais velho, ele era o aluno mais adiantado do grupo - estava na $9^{a}$ série do Colégio Arariense.

$\mathrm{O}$ participante $\mathrm{P} 4$ (menino, 15 anos) foi o que, quantitativamente, mais participou da atividade, respondendo três das cinco questões. Ele estuda no Colégio Arariense e está na $8^{a}$ série.

A participante $\mathrm{P}_{5}$ (menina, 14 anos), durante a atividade, comentou ser a mais nova do grupo. Mesmo assim, ela mostrou ter opinião e ser participativa em atividades em grupo. Ao trazer exemplos do seu dia a dia, ela demonstra confiança e abertura à mediadora.

A participante P6 (menina, 14 anos) permaneceu em silêncio praticamente durante toda a atividade. Ela apenas participou quando questionada diretamente pela mediadora. Pela resposta, transpareceu estar desinteressada em ouvir e participar do grupo - ao ser questionada sobre a tolerância/intolerância, ela apenas concordou com a fala de outra participante e complementou afirmando que "não sei explicar como isso acontece".

A participante $\mathrm{P} 7$ (menina, 14 anos) era a única estudante do Centro de Ensino Arimatéia Cisne, o que a deixou um tanto deslocada perante os demais colegas, que ao menos já se conheciam dos corredores escolares. Mesmo assim, ela mostrou participar e inclusive conversou com meninas próximas a ela.

A participante P8 (menina, 14 anos) participou ativamente do grupo focal, respondendo e estimulando os demais participantes. Ao falar, ela dirigia-se ao P2, que é seu colega de escola, terminando as frases com "né?", para que ele confirmasse sua fala. 
A participante $\mathrm{P} 9$ (menina, 14 anos) somente falou quando a mediadora dirigiu-se diretamente a ela. Durante a atividade, ela riu muito, inclusive das respostas dos demais colegas. A participante $\mathrm{P} 12$, inclusive, pediu para que ela permanecesse em silêncio, pois $\mathrm{P} 9$ ficou grande parte da atividade conversando com a colega P10 e com sua irmã, P11.

A participante P10 (menina, 15 anos) tentou integrar o grupo, mas foi atrapalhada por P9, que falava com ela constantemente. Mesmo assim, ela participou e deu opiniões. No começo, acompanhou P9 nas risadas e conversas, mas participou da atividade até o penúltimo momento.

A participante P11 (menina, 15 anos) conversou com sua irmã, P9, durante a atividade. Vê-se que quando P9 e P10 estavam conversando (no começo e ao final da atividade), P11 se autorizou a opinar no grupo.

A participante P12 (menina, 15 anos) apenas falou uma vez, fazendo todos rir com sua colocação sobre o comportamento das meninas de Arari/MA, afirmando que muitas delas apenas vão para a escola para namorar. Contudo, mesmo trazendo para a discussão esta questão importante, ela não fez mais observações. Inclusive, P12 deixou em branco seu retrato. Seu riso durante a atividade pode demonstrar certa intimidação perante o grupo, o que a motivou a não produzir o retrato.

\subsection{Discriminação}

Situações de discriminação são significativas no enredo do filme "Escritores da Liberdade", com destaque para os estranhamentos originados em diferenças étnicas e comportamentais. Estas situações, muitas vezes, fomentam o surgimento de situações de intolerância e desrespeito com o próximo. Na realidade dos jovens das duas cidades, tal situação foi apontada como recorrente e causadora de problemas dentro do ambiente escolar. As diferenças entre as realidades apareceram quando as razões da discriminação foram levantadas - enquanto em Santa Maria a ênfase é dada aos modos de vestir e falar, em Arari as motivações relacionam-se, especialmente, com questões sociais.

-A discriminação é uma maneira de excluir uma pessoa (P8 Arari, menina, 14 anos).

-Por causa da cor, do jeito de ser (P5 Arari, menina, 15 anos).

-Pela classe social, aqui existe (P8 Arari, menina, 14 anos).

-No meu colégio, por exemplo, tem [discriminação]. Porque tem gente que tem classe social mais alta, que acabam excluindo pessoas que não são assim. Eles ficam dizendo "tu é pobre, não pode comprar isso ou fazer aquilo". Isso por causa de diferença. (P8 Arari, menina, 14 anos).

-Jogam [a discriminação] na cara (P5 Arari, menina, 15 anos). 
A discriminação em Arari é discursiva e direta, como aponta a participante $\mathrm{P} 5$, ao afirmar que os preconceitos são "jogados na cara". As diferenças são ligadas diretamente aos conflitos entre diferentes classes sociais, entre distintas origens étnicas e pelo "jeito de ser". O comportamento é determinante para haver ou não a discriminação. Em Arari, para além da discriminação, há uma situação que é recorrente para aqueles que estão fora do padrão vigente - há a exclusão, que humilha e machuca.

$O$ poder aquisitivo mostra-se como elemento diferenciador - incluindo ou excluindo o sujeito, colocando o junto ao "nós" ou segregando-o e definindo-o como "eles". A diferença nos padrões de consumo estimula a discriminação em Arari, e sua expressão é facilmente perceptível. Há agressões verbais, e a classe social é capaz de deslegitimar uma pessoa dentro do grupo social.

As falas revelam um ponto significativo que diferencia as duas realidades o consumo de mídia e os padrões referenciais em Arari são diferenciados. O município maranhense tem elementos referenciais locais que ganham sentido e pesam na construção das representações dos jovens. A diversidade e a ação democrática promulgada pelo Bumba Meu Boi alcançam o dia a dia do povo, que se mostra mais aberto ao que é diferenciado.

A questão sexual também resultou em leituras diferenciadas na cidade maranhense. Em Arari, a diversidade sexual não segrega nem gera exclusão, visto que os jovens, diferentemente dos santa-marienses, nem tocaram no assunto. A diferença nas opções sexuais são naturalizadas e aceitas em sua grande maioria.

\subsection{Violência}

A consequência direta da discriminação, apontada pelo filme e evidenciada nas falas dos participantes, é a violência, em suas várias facetas. $O$ desrespeito ao outro gera inimizades e é capaz de criar situações delicadas dentro do espaço escolar. Ambos os grupos têm consciência dos desdobramentos possíveis da intolerância e da discriminação - a violência foi apontada como desfecho comum em situações de desrespeito.

-A violência pode ser lingüística, verbal, ou "literalmente". Aí, a pessoa faz sem saber das conseqüências (P5 Arari, menina, 14 anos).

-Assim machuca, às vezes até machuca mais [do que a física] (P9 Arari, menina, 14 anos).

-É igual ou até pior, comparando com o filme (P8 Arari, menina, 14 anos).

-Isso aqui ó [menino mostra marcas e cicatrizes em seu pescoço] é sinal de violência na escola. Eles esquentavam o 
ferro da cadeira e passavam aqui, por violência, por molecagem. Tudo foi por molecagem (P3 Arari, menino, 14 anos).

-Acontece por vingança mesmo, por ofender ou machucar alguém. É fazer qualquer coisa que humilhe (P10 Arari, menina, 15 anos).

A participante $\mathrm{P} 5$ define a violência com palavras vazias, sem significação conjunta e com vocabulário distante de sua realidade social. Contudo, ela consegue distinguir em sua fala duas formas usuais de violência - a física e a moral.

As motivações são as mais diversas possíveis, mas a referência unânime aponta para retaliações - as diferenças motivam ações onde há gratuidade na reação. Mesmo usual e cotidiana, acostumar-se com a violência é impossível para os jovens. A reclamação é uníssona em relação à prática e as consequências das respostas violentas.

As marcas deixadas pela violência são persistentes para os jovens. Assim como os participantes ararienses comentam, a ação violenta é, em grande parte das vezes, impulsiva e capaz de ferir profundamente. Usualmente "acontece por vingança", como afirma a participante P10. Situações como estas, que fomentam um espírito vingativo e de retaliação, mostram a necessidade de ações em prol da tolerância e da boa convivência dentro da comunidade escolar.

Semprini (1999, p. 50), conforme citado anteriormente, pensa as polêmicas multiculturais dentro da escola como forma de enriquecimento e reflexão para novos paradigmas. Então, através da reflexão e de ações em prol da recomposição do mundo (Touraine, 1997, p. 238), a violência deixa de ser opção final nos conflitos e realidade cotidiana. Em Arari, tal medida é latente dentro do espaço escolar.

Em Arari, a situação de violência física dispara como principal, conforme relatos dos participantes. A necessidade de abordar tais questões dentro do espaço escolar, tal qual faz Erin Gruwell no filme Escritores da Liberdade, mostra-se como ação necessária. A reflexão acerca da diferença e da tolerância com o que é diferente é necessária para fomentar novas realidades, onde o diálogo é recorrente e conciliador.

A participante $\mathrm{P} 9$ afirma que o abuso moral é capaz de ferir mais do que a violência física, aproximando-se das falas santa-marienses. Contudo, uma situação retratada pelo participante $P_{3}$ mostra que as reações violentas já estão naturalizadas entre os adolescentes. Ao mostrar as marcas da violência da qual foi vítima, os demais participantes mostram-se indiferentes, assim como o próprio agredido.

Ao classificar sua agressão como "molecagem", também o aluno demonstra naturalizar e, inclusive, aceitar certas violências. A humilhação causada pela violência moral ou as marcas deixadas pela violência física são duramente criticadas pelos jovens, embora a significativa fala de $\mathrm{P} 3$ aponte para 
uma naturalização do clima e da prática da violência no dia a dia escolar.

\subsection{Grupos de pertencimento}

A reunião dos jovens juntamente com seus pares cria grupos, que compartilham referências e valores simbólicos. A existência de tais agrupamentos foi confirmada pelos participantes do grupo focal, contudo, as razões que aproximam os jovens são distintas. Neste contexto, há situações de intolerância e preconceito que retomam Bobbio (2004, p. 207) e as formas de se considerar a diversidade, já citado no presente trabalho.

Em Arari, as aproximações são caracterizadas por outras finalidades namorar, conversar, estudar.

-Existe grupo, mas só para conversar. Cada um tem seu grupinho (P12 Arari, menina, 15 anos).

-O que a gente observa é que existe um grupo de menininhas que está entrando na fase de namoro e que querem ir uma mais bonitinha do que a outra, pra chamar a atenção dos meninos. Tem aquelas que não ligam muito para isso e que vão para a escola para estudar mesmo (P12 Arari, menina, 15 anos).

-Tem aquelas com cachorrinho cor de rosa, mais "empiriquitadinha", naquela fase de "bom pra cá, bom pra lá". Tem umas que não despertaram ainda. Aqui em Arari, na cara a gente percebe isso (P10 Arari, menina, 15 anos).

-Aqui [em Arari] é sempre assim, um quer ser mais que o outro (P8 Arari, menina, 14 anos).

-Um quer ter o que é do outro, e assim vai (P7 Arari, menina, 14 anos).

-Na minha escola o que mais tem é gente botando defeito nos outros (P10 Arari, menina, 15 anos).

Para os jovens ararienses, a escola é o principal espaço de sociabilidade, capaz de promover a construção de relações e a apropriação de valores. Os grupos existem, mas são formados por afinidades distintas de caracteres de identificação, como vestuário, gostos musicais ou compartilhamento de ideias. As aproximações, segundo P12, "são só para conversar". Contudo, também há falas que apontam segregações oriundas de diferenças sociais.

O principal ponto destacado pelos participantes, especialmente as meninas, é o interesse pelos meninos e a possibilidade de encontrar um namorado na escola. Há uma divisão entre as meninas, identificada por elas próprias - há aquelas que se interessam em estudar e comparecem a escola para isso e outras que têm outras intenções no ambiente escolar. Vaidade e cuidados com o visual preocupam as meninas que vão "empiriquitadinhas" para a aula, 
enquanto o outro grupo não se preocupa tão veementemente com questões estéticas. O espaço de sociabilidade que a escola promove necessita, então, abrigar e conviver com conflitos e disputas ligados a questões de sexualidade.

Há uma forte "cultura da fofoca", assim como uma referência direta ao "ter", assim como apontaram os participantes santa-marienses. "Um quer ter o que o outro tem", afirma a participante P7, complementada por P8, que lembra "sempre um quer ser mais que o outro". As duas falas se complementam para apontar uma característica do espaço escolar arariense - há uma grande disputa simbólica entre "ser" e "ter", e tal luta segmenta e hierarquiza sujeitos. Tal divisão ratifica as falas anteriores sobre discriminação, e mostra-se perpassada pelas questões ligadas a classe social. O poder aquisitivo é elemento que segrega e divide os jovens, em um contexto de competição. Seja ligada a conquista de um namorado, seja por questões financeiras, as diferenças são mais dramáticas, capazes de romper e/ou desestimular relações.

\subsection{Tolerância}

A relação com a alteridade ainda é cercada por julgamentos precipitados e pré-conceitos que tolhem, muitas vezes, as relações entre alunos e com os professores. As situações são delicadas, e apontam para características próprias de cada contexto.

-Varia, a gente está com um amigo, por exemplo, e aí chega outro que é mais amigo da gente, aí a gente dá mais atenção pra ele. Assim começa, a chegar mais perto ou a criar inimigos (P3 Arari, menino, 14 anos).

-A gente tenta conviver (P6 Arari, menina, 14 anos).

-Isso já gerou conflito na minha sala. Chegou uma menina lá no grupo que era meu e gerou muita briga. A novata gerou muita briga. Demorou um pouquinho, mas todo mundo percebeu que o pessoal prestava mais atenção nela, o que levou a uma briga enorme e fizemos as pazes de qualquer jeito (P5 Arari, menina, 14 anos).

-O mesmo que P5 falou acontece direto. É sempre a mesma coisa, não sei nem como explicar (P9 Arari, menina, 14 anos).

-Na minha sala, todos compartilham seus problemas uns com os outros, chega um novato e a gente conversa para que ele não se sinta solitário ou sozinho. Todo mundo ajuda. Na minha sala, a gente tenta conviver com as diferenças ( $\mathrm{P}$ 1 Arari, menina, 14 anos).

-Às vezes conseguimos conviver com as diferenças. Quando não, dá briga, e eu não sei o porquê, já que todo mundo deveria ser amigo, compartilhar com as pessoas (P4 Arari, menino, 15 anos). 
A proximidade e o reconhecimento do outro são pontos apontados pelos ararienses como fundamentais para a aproximação ou rejeição de alguém. Há um binarismo significativo entre os conceitos de "amigo" e "inimigo", "longe" e "perto", "igual" e "diferente". Há dificuldades na comunhão e na aproximação com novos sujeitos, e as diferenças são toleradas de forma já reportada por Bobbio (2004) no presente trabalho - há preconceitos já arraigados socialmente que influenciam diretamente nos comportamentos. As relações sociais ganham observações quantitativas para serem ou não viáveis. A relação de distância e proximidade é determinante no estabelecimento de relações e na distribuição entre "nós" e "eles".

A participante $\mathrm{P}_{5}$ afirma que a intolerância, em um primeiro momento, gerou conflitos em sua sala de aula. Uma colega nova foi o estopim de um conflito entre os demais colegas, contudo, a reflexão levou-os a uma postura mais aberta e tolerante. O diferente e o "outro", na história relatada por P5, significa a novidade e mostra o temor ao desconhecido. "Demorou um pouquinho (...) fizemos as pazes de qualquer jeito", afirma P5, que foi corroborada por P9.

Já a situação de P1 mostrou-se próxima da ideia construída por Silva (2009) para uma identidade de caráter político, capaz de estimular mudanças sociais. Na classe desta participante, os colegas dividem seus problemas uns com os outros, em um processo de crescimento conjunto e compartilhado. "Na minha sala, todo mundo tenta conviver com as diferenças", afirma ela, sendo exemplo de uma situação de exceção perante os demais exemplos.

Uma das situações que contrapõe a positiva realidade supracitada é a de P4, visto que há o desejo, compartilhado entre os colegas, de uma realidade pacífica e tolerante, contudo, muitas vezes conviver com as diferenças tornase delicado. Há dificuldades para compreender, para se expressar e para lidar com as complexas diferenças pessoais, do próprio grupo e dos outros.

\section{$2.8 \mathrm{Culpas} / \mathrm{medos} / \mathrm{vergonha}$}

Nesta discussão, os posicionamentos dos alunos ararienses e santa-marienses mostraram-se semelhantes, o que permite inferir que a cultura escolar prepondera na formação de referenciais dentro da sala de aula. A maioria compartilhou seus medos, culpas e vergonhas. A reprovação e os processos avaliativos surgem como razões principais para os temores compartilhados pelos alunos de Arari/MA e Santa Maria/RS.

-Tenho medo de errar (P10 Arari, menina, 15 anos).

-Eu não tenho vergonha (P1 Arari, menina, 14 anos).

-Tá, mas imagina chegar num lugar onde não se conhece ninguém e tem que tentar fazer amizade, e se eles não querem, eles vão ficar te zoando, você vai sentir vergonha (P10 Arari, menina, 15 anos). 
-Tenho vergonha dos meus pais (P11 Arari, menina, 15 anos).

-Assim, se tem um trabalho no colégio e está todo mundo lá, e você está apresentando o resumo de algum trabalho, por exemplo, e na hora você erra uma palavra. Todo mundo começa a rir, isso dá uma vergonha, né? Dá medo de ir novamente para o quadro apresentar outro trabalho (P8 Arari, menina, 15 anos).

-Também se passa vergonha quando se é humilhado. Falar errado, por exemplo. (P2 Arari, menino, 15 anos).

Há opressão e restrições no espaço dialógico, visto que os jovens próprios se desautorizam a expressar-se por temer a rejeição e a avaliação do outro. A rejeição em diferentes espaços sociais também é levantada pelos estudantes - após P1 afirmar não sentir vergonha, a participante P10 rebateu afirmando que "imagina chegar num lugar onde não se conhece ninguém e ter que tentar fazer amizade".

A reação dos demais pode impossibilitar novas participações pelo medo do julgamento dos "outros", dos pares e até dos familiares. Ao ser questionada sobre o que lhe traz medo, P11 afirmou sem demoras que tem medo de seus pais, o que pode apontar uma relação delicada ou pais autoritários perante a diferença. A culpa e a vergonha integram um processo que dificulta ou até impede o indivíduo de reconhecer a "si" e ao "outro" como sujeitos.

\section{CONSIDERAÇÕES FINAIS}

O multiculturalismo, quando analisado de forma crítica, leva a questionamentos acerca das origens das diferenças, das hierarquizações e privilégios, assim como leva a posicionamentos críticos à exclusão social (RIBEIRO, 2008, p. 131). Identificar as influências dos contextos culturais na construção e apropriação de representações de "eu", "outro" e do "mundo" foi o principal objetivo do presente trabalho.

Os contextos culturais influenciaram diretamente nas provocações feitas nos grupos focais. As falas dos jovens foram motrizes para tal diagnóstico, visto que, nas proposições feitas quando os temas centrais giravam em torno da tolerância e dos preconceitos, assim como de parte das falas de culpa/ medo/vergonha, exemplos e histórias locais ganharam espaço e peso nas suas interpretações.

A convivência no ambiente multicultural escolar desafia a Educação e a Comunicação a buscar linguagens e estratégias para enfrentar essa pluralidade de identidades em permanente re/construção. Silva (2009, p. 96-99) sugere como estratégia a afirmação da identidade política, sendo ela estratégia tanto pedagógica como comunicacional. Assim, também a proposta de Touraine (1997, p. 238) de recompor o mundo, transformando e alargando os horizontes culturais, torna-se possibilidade viável à convivência entre as diversidades. As 
ideias de Bobbio (2004) sobre a tolerância ganham sentido na busca de estratégias para que a identidade e a diferença tornem-se espaços de produção social.

Quanto à dialogicidade freireana no processo de aprendizagem, verificou-se que, de certa forma, a "cultura do silêncio", se perpetua, menos pelo autoritarismo dos professores, como predominava no passado recente, e mais pelo temor da reação e do julgamento dos colegas, da "gozação", medo de errar e ser "ridicularizado". O fenômeno detectado, então, é que convivem simultaneamente a "cultura do silêncio" com a "cultura do barulho", da dispersão, em grande parte reflexo de uma geração multimídia e algumas vezes representa uma resposta dos jovens a autoritarismos da estrutura escolar. Apesar de uma aparente harmonia, percebeu-se o ambiente escolar como espaço de diferentes conflitos que possuem como elementos centrais a questão da identidade e da diferença. A elaboração das identidades perpassa tal relação, e na escola, espaço de socialização e construção de conhecimentos e valores, torna-se necessária sua reflexão. Isso evidencia a necessidade da adoção de estratégias educomunicacionais para que a escola seja um espaço de aprendizado contemplando uma "ecologia de saberes".

\section{REFERÊNCIAS}

BOBBIO, Norberto. A Era dos Direitos. Rio de Janeiro: Elsevier, 2004.

MOTTA, Luiz Gonzaga. Análise Pragmática da Narrativa Jornalística. In: LAGO, Cláudia; BENETTI, Marcia (org.). Metodologia de pesquisa em jornalismo. Petrópolis: Vozes, 2007.

RIBEIRO, Sônia Tereza da Silva. O rap e a Aula: Tocando nas Diferenças... In: Revista da ABEM, V.19, s/n, 2008.

SEMPRINI, Andrea. Multiculturalismo. Bauru/SP: EDUSC, 1999.

SILVA, T. T. A Produção Social da Identidade e da Diferença. In: SILVA, T. T. (Org.) HALL, Stuart; WOODWARD, Kathryn. Identidade e Diferença - A Perspectiva dos Estudos Culturais.

Petrópilis/RJ: Vozes, 2009.

THORNTON, Ricardo. Grupos de Discussão. Grupos Focais. Metodologia. Tradução de Luciane D'Ávila de Moura e Leonardo Meira do Nascimento. Santa Maria/RS: FACOS/UFSM, 2005.

TOURAINE, Alain. Iguais e Diferentes - Poderemos Viver Juntos? Lisboa: Instituto Piaget, 1997. 


\section{Manuela Ilha Silva}

Possui graduação em Comunicação Social pela Universidade Federal de Santa Maria (2010). Tem experiência na área de Comunicação, com ênfase em Educomunicação, atuando principalmente nos seguintes temas: educação, comunicação, educomunicação, mediações e educação patrimonial.

\section{Rosane Rosa}

Doutora em Comunicação e Informação pela Universidade Federal do Rio Grande do Sul (2009), Mestre em Comunicação pela Universidade do Vale do Rio dos Sinos (2000), Especialista em Administração de Marketing pela UNISINOS (1993) e graduada em Relações Públicas (1990) e Jornalismo (1992) pela UNISINOS. Atualmente é professora adjunta do Departamento de Ciências da Comunicação da Universidade Federal de Santa Maria. 